\title{
Understanding the Regional Engagement of Universities from a Stakeholders' Perspective: The Case of the University of Thessaly, Greece
}

\author{
Maria Adamakou (D), Spyros Niavis *(D), Dimitris Kallioras and George Petrakos \\ Department of Planning and Regional Development, University of Thessaly, 38334 Volos, Greece; \\ madamakou@uth.gr (M.A.); dkallior@uth.gr (D.K.); petrakos@uth.gr (G.P.) \\ * Correspondence: spniavis@uth.gr; Tel.: +30-2421074398
}

Citation: Adamakou, M.; Niavis, S.; Kallioras, D.; Petrakos, G.

Understanding the Regional

Engagement of Universities from a Stakeholders' Perspective: The Case of the University of Thessaly, Greece. Sustainability 2021, 13, 10565. https:/ / doi.org/10.3390/su131910565

Academic Editor: João J. Ferreira

Received: 2 September 2021

Accepted: 20 September 2021

Published: 23 September 2021

Publisher's Note: MDPI stays neutral with regard to jurisdictional claims in published maps and institutional affiliations.

Copyright: (c) 2021 by the authors. Licensee MDPI, Basel, Switzerland. This article is an open access article distributed under the terms and conditions of the Creative Commons Attribution (CC BY) license (https:/ / creativecommons.org/licenses/by/ $4.0 /)$.

\begin{abstract}
International literature pays vast attention to the role and the regional engagement of universities as a facilitator of sustainable regional development. Most papers use top-down approaches by looking at how well conceptual models of a university's role fit any case study considered or by measuring predefined dimensions of university engagement. The present paper prioritizes the stakeholder views and provides a framework for revealing the critical dimensions of the university's regional engagement from a bottom-up perspective. The region of Thessaly is selected as a case study, and the university's engagement is conceptualized by a four-dimensional framework that considers the university's contributions, student roles, beneficiaries, and barriers. Then, through a survey, relevant items are provided to stakeholders to formulate any potential engagement factors. The factors are extracted using the principal component analysis, and then the consensus of different stakeholders on their response patterns is then also evaluated with relevant statistical tests. In practical terms, the analysis shows that a capable number of factors could be formulated under each dimension of the framework and that there are not many significant differences in stakeholder perceptions, regardless of their institutional role. In theoretical terms, the identified factors may act as a baseline for any future relevant evaluation.
\end{abstract}

Keywords: university role; sustainable engagement; principal component analysis; stakeholder analysis

\section{Introduction}

In the knowledge era, it is evident that higher education institutes (HEIs), such as universities, have acquired a vital role in fostering sustainable regional development [1]. In many instances, HEIs are seen as capable actors for promoting the goals of the regions where they function, and for this, traditional teaching and research activities are steered towards the fulfillment of local needs and targets [2]. Through knowledge generation, universities can ensure the sustainable development of regions and can affect various instances of the social, economic, and cultural life as well as the environment of their hosting regions [3,4]. Therefore, there is a shift in knowledge production from the traditional Mode 1 type to Mode 2, in which research is more closely related to regional needs [5]. In order for universities to fulfill their role as drivers of regional development, they should engage with the region and should establish networks and partnerships with other regional actors, both public and private, who are working in the same direction [6]. This more active role in promoting regional targets can be seen as the third mission of universities [7].

The weight that each university places on various activities and missions, the level of their engagement with the region, and the forms of partnerships and networks that universities take part in shape their role and the type of impacts that they bring to the regions where they are located (See Table 1) [8]. Youtie and Shapira [9] conceptualized the evolution of universities from pure knowledge generators, functioning above society, to knowledge 
hubs that are fully engaged in the regions where they are situated, putting a premium on promoting local capabilities. Uyarra [8] sees five main roles for the universities: the generation of knowledge, the exchange of knowledge, the commercialization of research, the establishment of systems and networks, and the enhancement of local development. Finally, Trippl et al. [3] distinguish, two broad views on the role of universities. The first view has a narrow focus, as it considers universities whose activities have an economic or technological dimension. Within this view, the entrepreneurial and regional innovation dystem (RIS) universities are distinguished. The second view is broader, considering roles that also take into account wider targets. Two leading roles are conceptualized under this view, namely the Mode 2 and the engaged university.

Table 1. Indicative conceptualizations of university roles.

\begin{tabular}{cccc}
\hline Authors & Youtie and Shapira [9] & Uyarra [8] & Trippl et al. [3] \\
\hline & Storehouse of Knowledge & Knowledge "factory" & Rntrepreneurial University \\
Roles & Knowledge “factory" & Relational University & Regional Innovation System (RIS) University \\
& Knowledge Hub & Entrepreneurial University & Mode 2 University \\
& & Systemic University & Engaged University \\
\hline
\end{tabular}

The relevant literature has also extensively reviewed the different domains that a university's operation may affect in the region where it is based [6]. Florax [10] distinguishes eight different fields on which university operations have an effect. These domains include the economy, politics, demography, infrastructure, culture, regional attractiveness, education, and other social aspects. Chatterton and Goddard [2] find that universities can boost regional development by connecting their function (teaching, research, and service to the community) with regional skills, innovation, and community. In addition, at the city level, Stachowiak et al. [11] find that universities can have an impact on businesses, through the transfer of technology and innovation; the community, by providing social services, and continuous education; city development, through contributions to policymaking; and culture, via cultural services and the empowerment of city life. As for the economic benefits, Goldstein et al. [12] find eight functions that can benefit regional economies, namely the creation of knowledge, human-capital creation, transfer of existing know-how, technological innovation, capital investment, regional leadership, knowledge infrastructure production, and influence on regional milieu [13].

The international literature is rich in studies capturing the role and estimating the impacts of universities in an empirical context using case studies. Trippl et al. [3] used their four-roles concept to compare the educational policies of the UK, Sweden, and Austria. Many other scholars concentrated on indicators to evaluate the university's role in promoting different societal targets. Perry et al. [14] focused on North Carolina; Holton et al. [15] focused on the USA; Frondizi et al. [16] focused on Italy; and Sedlacek [17] focused on Graz, Austria, to evaluate the level of engagement and the fulfillment of the third mission of universities, which is their role as promoters of regional development. In addition, many studies, such as those of Mehling and Kolle [18], Filho et al. [19], and Demele et al. [20], assessed the role of universities in promoting sustainability in the regions where they are located and, most importantly, the enhancement of regional capabilities to achieve the United Nations Sustainable Development Goals [21]. In addition, a broad stream of studies concentrates on the estimation of the economic benefits through input-output analysis and multiplier effects $[6,22,23]$. Finally, there are also unique approaches to measure the contribution of universities on partial dimensions of sustainable development, such as social innovation [7], better actor cooperation [24], entrepreneurial capacity building [25], the promotion of creative economy [26], and environmental sustainability [27].

Regardless of the field and targets of university intervention, active cooperation and developing partnerships with local actors are prerequisites for successful engagement [28]. 
Therefore, it is critical for the role of universities to be clearly defined on par with regional pursuits and goals [29]. As Goddard and Kempton ([30], p. 1) state:

"... too often partnerships fail because university managers do not understand the challenges of regional development and regional authorities do not understand the core mission of universities and the constraints within which they work."

Existing studies can provide valuable information about university contributions to their regions. Nevertheless, some gaps remain regarding the potential of the existing methodologies for shedding full light on the actual role of universities. As Trippl et al. [3] state, the limits among the various conceptual models are not always clear when real case studies are considered. Moreover, many of the studies based on indicators and quantitative data mostly concentrate on individual aspects of university contributions, be it social, economic, governance, or environmental issues. Moreover, quantitative approaches become narrow-focused due to the limitations imposed by the availability of data to quantify all kinds of university contributions. Therefore, more holistic approaches to define university roles and engagement should be developed. Such types of approaches should not only focus on the contribution of universities to regional development, they should also consider aspects such as the barriers to cooperation so that universities and regional authorities can develop well-informed strategies.

To do so, it is critical to incorporate the views of the stakeholders in the regions where the contributions and roles of universities are to be evaluated. Despite the undisputed significance of stakeholder perceptions and their relationships with the universities [31-33], there is still a gap in studies that incorporate stakeholder analyses into evaluating university contributions and the definition of their role. To fill this gap, the present paper builds on the pool of regional stakeholders, and through a dedicated survey, it seeks to record and codify their perceptions regarding the overall engagement of the university with the region.

The case study is performed in the region of Thessaly, Greece. Engagement is examined through a novel conceptual framework of four different dimensions: the perceived contribution of the university, the type of main beneficiaries, the perceptions of the role of students, and the barriers to cooperation. The survey is based on a range of questionsitems, which are considered as relevant to describe each dimension, following the relevant literature and the strategic documents of the University of Thessaly. Then, a principal component analysis (PCA) is conducted to group the questions-items into a smaller number of factors, which could provide a more general categorization of stakeholder views. By doing so, the paper follows a more bottom-up approach in defining the role and contribution of universities than other studies, following a more deductive top-down approach based on the evaluation of the level of application of general models in the regional context under consideration. In this way, the paper enriches the relevant literature with additional knowledge regarding university roles and potentially complements existing studies with new unexplored features.

Further to extracting common perceptions through various factors, this paper also seeks to explore the level of alignment among the views of different types of stakeholders. Three main types of stakeholders are recognized and are composed of representatives of the university, the local and regional authorities and civil society, and the business sector. The level of agreement is tested based on non-parametric tests based on the factor scores of each type of stakeholder and the mean values of the items being loaded on each factor.

Considering the previous remarks, this paper seeks to provide answers to the following two research questions:

(1) Can stakeholder perceptions be used to provide distinct dimensions of a university's roles and engagement in the region?

(2) Are there any differences among stakeholder perceptions regarding the university's roles and engagement in the region? 
The paper is structured as follows: In Section 2, the methods for conducting the empirical analysis are presented and discussed. Section 3 presents the results of the analysis. Finally, in Section 4, the main results and the theoretical and policy implications of the results are discussed.

\section{Conceptual and Empirical Framework}

The present section describes the conceptualization of the university's engagement evaluation and provides details for the methodology followed for conducting the survey and for analyzing its results.

\subsection{Conceptualizing University's Regional Engagement}

The conceptual model of the paper is presented in Figure 1. Four dimensions approach the overall engagement of the university. The first three dimensions are more closely related to the role of the university, while the fourth considers the barriers for the higher engagement of the university.

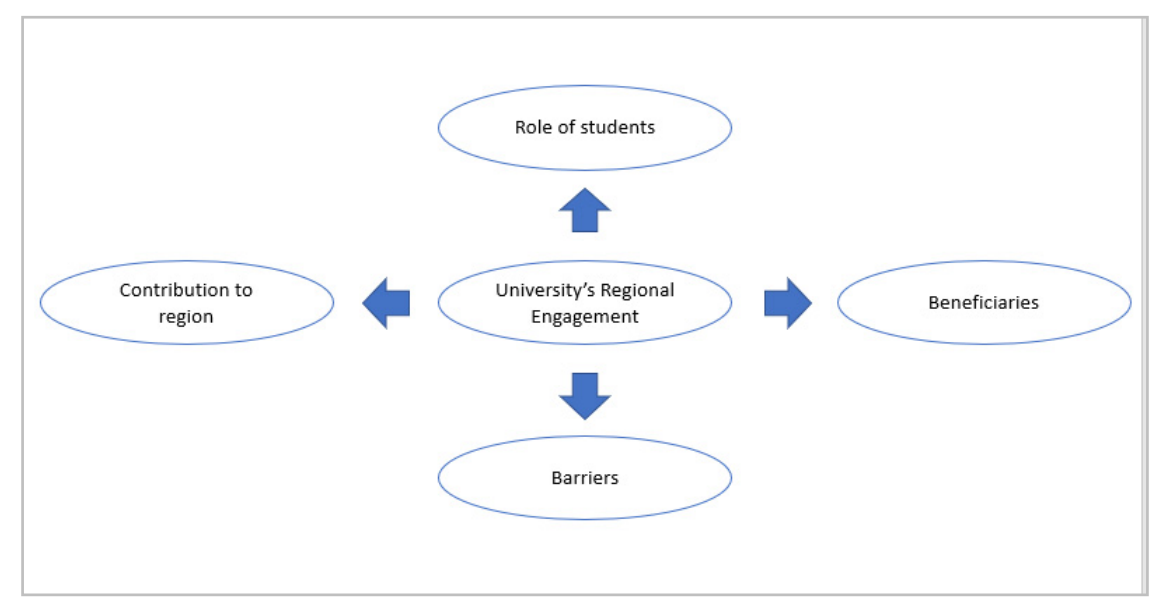

Figure 1. Conceptualization of a university's perceived regional engagement.

The first dimension concerns the contribution that the university makes to the region. In total, 14 items regarding the potential contributions of a university were provided to the respondents (See Table 2). The items were composed by considering the changes that the three main missions of universities, namely teaching, research, and service, could bring to the community and to the region under consideration. To select the items, the paper of Chatterton and Goddard [2] on the interactions between the university's mission and regional components and the work of Trippl et al. [3] on the various roles of universities were mainly considered. Moreover, a wording analysis of the university's strategic plan was used for this purpose. The main goal of elaborating this dimension is to recognize any distinct elements of university contributions to the regional community.

The second dimension of a university's roles is related to the students and how the stakeholders perceive their role in promoting regional goals. Students are among the most valuable stakeholders of universities [33] and are a source of positive change for regions by increasing their innovation capacity, improving their human capital, strengthening regional tolerance, empowering creativity, and sustaining economic growth through direct and indirect spending $[34,35]$. It is noticeable students contribute to regional development either by improving the capacity of the region to be more competitive or by increasing regional demand for goods and services. To extract some factors expressing the perceptions of regional stakeholders regarding the role of students, eight items were provided (See Table 2). 
Table 2. The questions and items of the questionnaire.

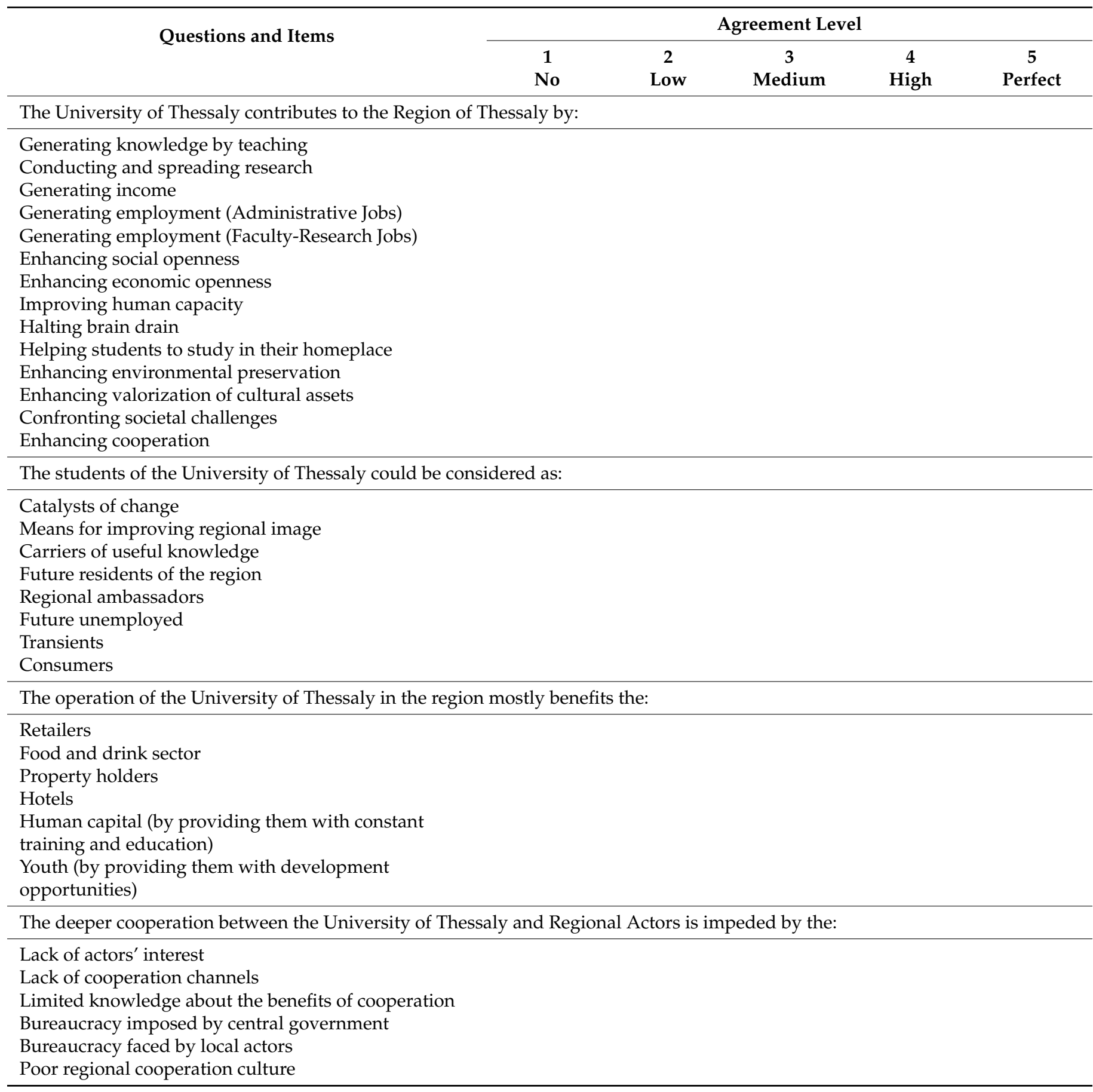

The third dimension of a university's roles regards the most important beneficiaries by its presence in the region. As it was stressed throughout the introduction, universities create many benefits in the regions where they are situated. Nevertheless, the type of activities and partnerships that the university chooses to engage in may have a differentiated effect on regional actors. Deiaco et al. [36] recognize three types of actors, namely students, firms, and the government, which may receive the benefits of the core university activities of teaching, research, and service to society. Nevertheless, when benefits are to be examined in a holistic context, other beneficiaries resulting from the development of links between the university and many sectors should also be considered [37]. Any comparisons among the different perceptions of beneficiaries may lead to useful conclusions about how local 
stakeholders see the function of a university: either as an income generator or as a power of change and improvement. Six types of beneficiaries were provided to the respondents in order to assess the magnitude of the benefits that they acquire from the university (See Table 2).

Finally, the fourth dimension first refers to the barriers that may impede the deeper engagement of the university to the regional system. Many types of barriers may exist, which can be either internal or external to the university's operation. According to Goddard and Kempton [30], barriers may arise from the university's limited ability to reach the regional stakeholders or from the limited willingness of regional actors to receive the outputs of the university. Koryakina et al. [38], through a survey of the managers of two Portuguese universities, recognized the following barriers in university engagement: The lack of incentives for faculty members to promote the university's third mission; the scarcity of funds, the lack of entrepreneurial culture, both in the institution but also in the actors of its external environment; the lack of dedicated managerial structures; and the ineffective legislation. For the purposes of this paper, six different items regarding these barriers, both from the internal but also from the external environment of the universities, were provided to the respondents so that they could be evaluated (see Table 2).

\subsection{Empirical Analysis Framework}

All of the items provided to the stakeholders were measured with a 1-5 Likert scale, with 1 revealing total disagreement with the statement and 5 revealing perfect agreement. The questions and the items that were provided are presented in Table 2.

For each dimension, PCA and Varimax Rotation were implemented to construct the factors [39]. PCA is a method of factor analysis, and it assumes that distinct factors can be constructed by considering the variation of the measured variables. In this manner, it is very useful for reducing and codifying existing information and for explaining the variation of the phenomena under consideration in a parsimonious context [40]. The use of PCA in the present paper can provide the research strand around university engagement with the region with additional information and bring to light new dimensions of university roles for regional development to be tested elsewhere. It can also summarize any scattered approaches to evaluate the engagement of universities that are present in the relevant literature in compact dimensions. For each application of the factor analysis, initially, the results of two diagnostic tests are provided. First, the value of the Kaiser-MeyerOlkin (KMO) measure of sampling adequacy is reported. The KMO measure takes values between 0 and 1 , with values closer to 1 denoting a good fitting of the model because the considered variables share a good amount of common variance. It is advisable to report the results of PCA when the KMO value exceeds 0.50. The second test is the Bartlett's test of sphericity, which compares the observed correlation matrix to the identity matrix. The null hypothesis of the test is that no correlation among the variables exists, and therefore, PCA is only performed when the null hypothesis is rejected based on a chi-square test $[40,41]$.

In addition, for every factor, the loadings of each variable on it will be reported, together with the overall proportion of the variation that the factor explains. Moreover, the Cronbach's alpha measure of the reliability of the variables included in each factor is also reported. Although there is not a consensus regarding the acceptable values of the Alpha measure, in general, Alpha values higher than 0.7 and lower than 0.9 could be considered as adequate. In addition, values between 0.6 and 0.7 are acceptable, while values under 0.6 denote that there is a lack of internal consistency among the respondents' replies [42,43]. Moreover, the mean values of the set of variables loaded on each factor are also presented on par with the standard deviation.

Finally, for the second research question, the factor scores extracted by the PCA are used to test the hypothesis of the common distribution of replies among different types of stakeholders. In order to obtain the factor scores, standard regression analysis with a mean of 0 and a variance equal to the squared multiple correlations between the estimated factor scores and the true factor values provided by the SPSS 25 software is used $[39,44]$. The tests 
among the types of stakeholders were performed using the Kruskal-Wallis specification. More precisely, Kruskal-Wallis is a non-parametric approach for testing the null hypothesis when two or more different samples are extracted from the same distribution. The test is based on the ranks of the observations, and it is the equivalent of the one-way analysis of variance (ANOVA). It is preferred from ANOVA when the observations do not follow normal distribution [39].

\subsection{Stakeholders Selection}

A comprehensive evaluation of university engagement should incorporate the views of all stakeholders, which shape the university's missions and activities but also shape those being affected by its operation. In order to define the most relevant stakeholders to perform the case study with, the paper builds on the classifications of stakeholders provided by Burrows [45] and Jongbloed et al. [46]. The stakeholders are first divided into internal and external, according to their relationship with the university (see Table 3). The external stakeholders are further classified into two distinct categories. The first category includes all stakeholders representing local and regional authorities, civil society, the church, environmental organizations, and parliament members who have been elected into the region under consideration. The second category of external stakeholders includes those in the business sector, including large enterprises and industries, chambers of commerce, professional federations and associations, and cooperatives.

Table 3. The characteristics of stakeholder survey sample.

\begin{tabular}{|c|c|c|c|c|c|}
\hline $\begin{array}{c}\text { Stakeholder } \\
\text { Category }\end{array}$ & Stakeholder Type & Role & $\begin{array}{c}\text { Invitations } \\
\text { Sent }\end{array}$ & $\begin{array}{l}\text { Replies } \\
\text { Received }\end{array}$ & Final Sample \\
\hline \multirow{6}{*}{ Internal } & \multirow{6}{*}{ University } & Rector Board & 5 & 2 & \\
\hline & & Deans of Faculties & 8 & 4 & \\
\hline & & Presidents of Departments & 34 & 10 & \\
\hline & & Directors of Research Institutes & 4 & 2 & \\
\hline & & Representatives of Employees & 1 & 1 & \\
\hline & & Total & 52 & 19 & 17 \\
\hline \multirow{11}{*}{ External } & \multirow{6}{*}{ Civil Society } & Parliament Members & 22 & 1 & \\
\hline & & Regional Authority & 13 & 4 & \\
\hline & & Local Authorities & 5 & 5 & \\
\hline & & Environmental Organizations & 3 & 2 & \\
\hline & & Church & 4 & 4 & \\
\hline & & Total & 47 & 16 & 15 \\
\hline & \multirow{5}{*}{ Business Sector } & Enterprises & 26 & 7 & \\
\hline & & Chambers & 6 & 5 & \\
\hline & & Professional Associations and Federations & 12 & 6 & \\
\hline & & Cooperatives & 11 & 2 & \\
\hline & & Total & 55 & 20 & 18 \\
\hline \multicolumn{3}{|c|}{ Total } & 154 & 55 & 50 \\
\hline
\end{tabular}

\subsection{Survey Implementation}

The views of stakeholders were gathered through a dedicated questionnaire (See Table 2). Due to the COVID-19 pandemic, the procedure was implemented online using the Google Forms platform. In total, 154 invitations for participation were sent, and 55 responses were collected (See Table 3). The low response rate could be attributed to the turbulence caused by the pandemic. Especially for the business sector, many reminders through email and personal communications were made to gather a sufficient number of replies to keep the sample balanced with regard to the three stakeholder categories. Finally, 50 responses providing full replies to all of the questions were used to perform the statistical analyses. 


\section{Results}

Section 3 describes the context of the case study and presents the main results of the application of the proposed methodology to the sample of the survey. The results are presented based on the two research questions of the paper. Therefore, the first part of the results analysis considers the presentation of the factors extracted from each dimension of the university's regional engagement framework. The second part presents the analysis results on the differences among stakeholder perceptions, thus providing answers to the second research question.

\subsection{Presentation of the University of Thessaly}

The University of Thessaly is situated in the region of Thessaly, Central Greece. The region has a population of 718,640 inhabitants, accounting for the $6.8 \%$ of the total population of Greece. In administrative terms, the region has five provinces: Larissa, Magnesia, Trikala, Karditsa, and the Sporades insular province. The largest cities are Larissa and Volos. For the year 2018, the gross domestic product per capita was estimated at 16,400 (in purchasing power standards). This figure lies below the national and European average GDPpc, which is estimated at 21,100 and 30,000, respectively. The tertiary sector is the dominant one, but the region also shows high specialization in the primary sector, as agricultural activities provide a great deal of employment to the regional population and generate about $12 \%$ of the regional gross value added, the highest figure among all of the Greek regions $[47,48]$.

The University of Thessaly was founded in 1984 and is currently the largest employment provider in the region. It consists of eight faculties and 37 departments, all of which are basic scientific fields, providing 71 post-graduate and PhD programs. It has premises in all of the mainland provinces and more than 42,000 undergrads, 4200 graduates, and $1400 \mathrm{PhD}$ students. Finally, it employs 1000 teaching and research staff and 450 members of administrative staff [49].

The university continues to improve its competitive position. Based on the World University Rankings, it is ranked among the 600-800 top universities in the world and 3rd among the country's universities. Based on the University Ranking of Academic Performance (https: / / www.urapcenter.org/, accessed on 20 August 2021), the University of Thessaly is among the $5 \%$ of the top European universities [50]. The University embraces the 3rd mission, and in the description of its action program, it is stated that:

"For the implementation of this Program we seek strategic alliances and the maximum possible support from society and the State. The development of the University is in the long run the most profitable investment that can be made in the region, as it is characterized by significant multiplier effects and as it impregnates the social and productive fabric with the most valuable factor of production: knowledge." [51]

\subsection{The Results of the PCA Analysis-Extraction of Factors}

The results of the PCA are presented in Table 4 . The KMO value is satisfactory for the analysis of the first three dimensions but is lower for the Barriers dimension. Nevertheless, considering that the value does not fall very short of the 0.7 threshold $(0.6)$ and that the null hypothesis for the Bartlett test of sphericity was rejected at the $<0.01$ significance level, the results of all four PCA analyses are presented and discussed. As for Cronbach's reliability analysis, all of the factors show values exceeding the 0.6 threshold with the exception of one factor of the Students dimension, which slightly exceeds the 0.53 . Finally, all of the factors explain a satisfactory amount of variance, with the highest being explained by the factors of the Beneficiaries dimension ( $>78 \%$ ) and the least by the factors of the Barriers dimension (58.85\%). 
Table 4. The dimensions and factors extracted by the application of PCA.

\begin{tabular}{|c|c|c|c|c|c|c|c|}
\hline Dimensions/Factors/Items & KMO & $\begin{array}{c}\text { Bartlett } \chi 2(* * * \\
\text { Sig }<0.01 \\
\text { Level })\end{array}$ & $\begin{array}{l}\text { Factor } \\
\text { Loadings }\end{array}$ & $\begin{array}{c}\text { Explained } \\
\text { Variance }(\%)\end{array}$ & $\begin{array}{l}\text { Cronbach's } \\
\text { Alpha }\end{array}$ & Mean & St. Dev \\
\hline Contribution & 0.84 & $372.96 * * *$ & & & & & \\
\hline Enhancing Human Capital & & & & 25.50 & 0.88 & 3.43 & 0.81 \\
\hline Enhancing social openness & & & 0.85 & & & & \\
\hline Enhancing economic openness & & & 0.80 & & & & \\
\hline Improving human capacity & & & 0.77 & & & & \\
\hline Halting brain drain & & & 0.71 & & & & \\
\hline Confronting Regional Challenges & & & & 24.98 & 0.87 & 3.66 & 0.75 \\
\hline Enhancing environmental preservation & & & 0.87 & & & & \\
\hline Enhancing valorization of cultural assets & & & 0.84 & & & & \\
\hline Confronting societal challenges & & & 0.73 & & & & \\
\hline Conducting and spreading research & & & 0.60 & & & & \\
\hline Enhancing cooperation & & & 0.60 & & & & \\
\hline Boosting Income and Employment & & & & 17.55 & 0.72 & 3.76 & 0.60 \\
\hline Generating income & & & 0.77 & & & & \\
\hline Helping students to study in their homeplace & & & 0.72 & & & & \\
\hline Generating employment (Administrative Jobs) & & & 0.62 & & & & \\
\hline Generating employment (Faculty-Research Jobs) & & & 0.54 & & & & \\
\hline Generating knowledge by teaching & & & & & & 4.68 & 0.47 \\
\hline Perceptions for Students & 0.77 & $165.92 * * *$ & & & & & \\
\hline Organic Elements of Development & & & & & & & \\
\hline Means for improving regional image & & & 0.94 & 42.03 & 0.87 & 3.50 & 0.68 \\
\hline Catalysts of change & & & 0.87 & & & & \\
\hline Regional ambassadors & & & 0.81 & & & & \\
\hline Carriers of useful knowledge & & & 0.79 & & & & \\
\hline Future residents of the region & & & 0.64 & & & & \\
\hline External Factors to Region & & & & 20.54 & 0.53 & 2.61 & 0.64 \\
\hline Future unemployed & & & 0.74 & & & & \\
\hline Transients & & & 0.72 & & & & \\
\hline Consumers & & & 0.62 & & & & \\
\hline Beneficiaries & 0.68 & $158.53 * * *$ & & & & & \\
\hline Economic Actors & & & & 48.11 & 0.86 & 3.35 & 0.61 \\
\hline Retailers & & & 0.90 & & & & \\
\hline Food and drink sector & & & 0.87 & & & & \\
\hline Property holders & & & 0.86 & & & & \\
\hline Hotels & & & 0.74 & & & & \\
\hline Human Capital and Youth & & & & 30.73 & 0.84 & 3.86 & 0.90 \\
\hline $\begin{array}{l}\text { Youth (by providing them with development } \\
\text { opportunities) }\end{array}$ & & & 0.93 & & & & \\
\hline $\begin{array}{l}\text { Human capital (by providing them with } \\
\text { constant training and education) }\end{array}$ & & & 0.90 & & & & \\
\hline Barriers & 0.60 & $45.33 * * *$ & & & & & \\
\hline Lack of cooperation culture & & & & 30.40 & 0.66 & 3.29 & 0.80 \\
\hline Lack of actors' interest & & & 0.86 & & & & \\
\hline Poor regional cooperation culture & & & 0.85 & & & & \\
\hline $\begin{array}{l}\text { Limited knowledge about the benefits of } \\
\text { cooperation }\end{array}$ & & & 0.59 & & & & \\
\hline Structural cooperation weaknesses & & & & 28.45 & 0.61 & 3.06 & 0.78 \\
\hline Bureaucracy imposed by central government & & & 0.73 & & & & \\
\hline Bureaucracy faced by local actors & & & 0.78 & & & & \\
\hline Lack of cooperation channels & & & 0.72 & & & & \\
\hline
\end{tabular}

The PCA analysis for the Contribution dimension initially returned four distinct factors. Since the option of Generating Knowledge by Teaching accounted for a factor itself, the analysis was repeated with the omission of this variable. The extracted factors also remained the same in the second analysis, as the items loaded on each factor did not change, and the proportion of explained variance remained almost equal. As it can be seen, apart from teaching, the stakeholders recognize three other roles of the university. The first is regarding the enhancement of the human capital, as all of the loaded items are related to the ability of the university to bring structural improvements in terms of the capital of the region, with contributions such as the enhancement of regional openness, the improvement of human capacity, and the halting of brain drain through the improvement of the potential of the youth population to find employment in the region. 
The second factor includes all of the items that relate to the confrontation of regional challenges. This factor recognizes the university as an organic part of the region and as a useful actor for dealing with all of the significant issues that the region is faced with, be it societal, environmental, or cultural. It is very interesting that the items of enhancing cooperation and spreading research results are loaded in this factor. Therefore, stakeholders recognize that research and all cooperation channels opened by the university should be mainly driven in a way that increases the capacity of the region to deal with its challenges. It could be said that according to the considered stakeholders, the third mission is thematically defined. The third factor accounts for pure economic contributions. Under this factor, the university is seen as a generator of employment and income. Further, it is perceived as a valuable means for allowing students to study in their home areas and therefore saving resources that would be spent outside of the region (if they had to study in other areas of Greece or elsewhere).

Finally, as it was noted before, teaching was loaded in a one-item factor. This result shows that stakeholders recognize teaching activities as a universal contribution of the university that should not be narrowed to any of the other contributions. As it was also shown, this was not the case with research activities. The recognition of the teaching role as an essential and general activity of the university is also testified from the fact that this item had the highest mean value (4.68). The second highest mean value was found for the ability of the university to boost income and employment in the region.

For the Students dimension, PCA returned two main factors. The factor explaining most of the variance is composed of items that assign a key role for students in the development of the region. In this factor, students are seen as catalysts of change due to their useful knowledge. They are also regarded as ambassadors of the region and as means for improving its image. Finally, under the prism of this factor, students are considered as future residents of the region. These characteristics demonstrate that students could be regarded as organic elements of development and are fully engaged with the region under this factor. The second factor consists of pessimistic and materialistic views of students. These factors are loaded variables that demonstrate perceptions of students as future unemployed members of the population, consumers, and transients. These views show a more neutral stance against students, which are only considered a means for income generation without any potential for engaging in the region. Students are mostly seen as external elements of regional development.

For the Beneficiaries dimension, two factors were also extracted by the PCA. The first factor explains about half of the variance. It is composed of items that demonstrate that the university's main beneficiaries are economic actors, such as retailers, the food and drink sector, property holders, and the hotel sector. This factor accommodates a rather narrow perception of beneficiaries in contrast with the second factor, which recognizes that the beneficiaries of the university are the youth and the people of the region, as the activities of the university improve their knowledge and capacities. The second factor is more closely related to the third mission of universities, which is the expectation of what they should bring to a region.

Finally, in the Barriers dimension, there are two types of barriers that are recognized by the stakeholders. The first barrier is more related to attitudes and considers the overall cooperation culture of the region. Issues such as the lack of actor interest, the poor regional cooperation culture, and the limited knowledge about the benefits of cooperation are grouped under this factor. On the other hand, the second factor could be seen as more structural, as it refers to the lack of established cooperation channels and bureaucratic burdens. Stakeholders recognize that both local bureaucracy but also bureaucracy imposed by the central government impede the higher engagement of the university and its deeper cooperation with regional actors. 


\subsection{Testing for Differences among the Stakeholder Groups' Perceptions}

After extracting the factors for each dimension, it is interesting to test for any possible differences in the distribution of the factor scores and mean values among the three stakeholder groups. The results of the Kruskal-Wallis test showed that no statistically significant differences exist on the rank sum of the factor scores among the three types of stakeholders, except for the second factor of the Barriers dimension (structural cooperation weaknesses), where a difference at the $<0.05$ significance level was found. To further investigate the differences among groups in this factor, three pairwise Mann-Whitney tests were implemented. The results showed statistically significant differences between the stakeholders of the university and those of the other two groups. The mean ranks of the university representatives were lower in both cases, showing that structural weaknesses are recognized as huge barriers, mainly by non-university stakeholders. In addition, this hypothesis was tested by applying the Bonferroni correction, and in this case, only the difference between the university and civil society stakeholders retained its statistical significance. As for the mean factor values, all of the Kruskal-Wallis tests returned no statistically significant results. The extracted results demonstrate that common perceptions regarding the engagement of the university to the region exist among the various types of regional stakeholders.

\section{Discussion and Future Research Directions}

The paper sought to provide an innovative conceptualization of university engagement with their regions. The innovativeness of the present analysis lies in the fact that instead of testing the fitting of different types of roles in the context of the case study, it followed the opposite direction by providing various options to the regional stakeholders in order to allow the various dimensions of engagement to be freely developed. This bottom-up approach complements the already rich existing literature on university regional engagement with a new methodological option, which has been scarcely incorporated in pervious analyses. Engagement was conceptualized as a mix of four dimensions, each composed of a different number of factors.

The current approach could be beneficial for academics and practitioners who are interested in the role and engagement of universities because it sets the basis for any dialogue among the university and other regional stakeholders to be implemented on a scientific basis where the fields of convergence and divergence would be clear to all interested parties. Moreover, it provides a useful guideline for any quantitative or qualitative evaluations of a university's engagement to be performed on a predefined scheme and in various spatial contexts. Finally, it can help universities and regional authorities to draft well-informed strategies and action plans.

The case study highlighted the perceived engagement level of the University of Thessaly to its region. For all of the dimensions, there were at least two different angles and views, as demonstrated by the extracted number of factors. As far as the role of the university is concerned, it became apparent that there are many and different perceptions of the role of the university by society. Therefore, further to its teaching role, the local community expects that the university will improve human capital, enhance mobility, help local actors confront regional challenges, and provide the region with employment positions and income. The university could capitalize on the information extracted by the paper to adjust its strategy, be it new departments, new curricula, and research avenues or partnerships, to better fulfill its role in each dimension. Moreover, the knowledge of the beneficiaries gained by the present analysis could help the university demonstrate its contribution to the area and establish its role as a critical actor of the region.

As for the students, the results signify their importance to the region. Students can play a major role in many instances of regional development. This should be clearly and constantly communicated to the regional stakeholders. An emphasis should be given to actors and citizens with a neutral stance against students to achieve their wider acceptance by society as catalysts of change. Moreover, the university could build on the recognition 
of the role of students to secure the essential funding to support any student activity that might benefit the region. The perceived barriers highlight the future steps for improving the cooperation of the university with the regional actors. The university, mainly building on its know-how, should trigger the discussion on how to improve the cooperation culture in the area and draft well-defined action plans. As for the structural weaknesses, the role of the university is equally important, as it should provide all of the available options and actions that could eliminate them. Furthermore, for this specific dimension, a constant dialogue should be implemented for the different parts to understand the factors behind the divergence of views on the issue.

Overall, the good knowledge of the expectations and the shortcomings of the university's engagement could help authorities operationalize its empowerment and steer funds towards this direction. The overall high level of stakeholder view compliance provides a fertile ground for common activities to be implemented towards the further engagement of the university. Moreover, the dimensions and the corresponding factors extracted by the paper could act as the basis on which a monitoring and evaluation framework would be developed to measure the progress of university engagement. It could also be the basis for enhancing and communicating the university's corporate responsibility, which will further empower its position and contribution to the area.

In methodological terms, the analysis could be considered as the first step for the bottom-up definition of the engagement level of the university. The engagement here was conceptualized as a set of various dimensions; therefore, the paper manages to summarize many scattered relevant approaches on the issue that have been considered up until now. This is a very crucial step in conducting applied research on the definition of the role of the universities, as it allows the comparison of the results of any future case studies. It should be noted that the present results were extracted by an explanatory factor analysis method. Therefore, future studies could replicate the survey in order to validate the present findings in other contexts. On this, confirmatory factor analysis models could be very enlightening.

Moreover, the present framework could be complemented with additional dimensions that have not been considered by the present paper. A dimension of potential improvements of both the university and the regional stakeholders could be added to make the framework more comprehensive. Additionally, additional items could be added to each dimension for any new factors that arise. In this way, the understanding of engagement will become richer and better adapted to the context and the particularities of the regions that are going to be implemented. Regardless of the final form of the framework, an evaluation scheme with indicators quantifying all of the factors could help regional actors monitor the university's engagement progress. Thus, the comparative evaluation of the perceived and actual level of engagement could be considered as a promising future research direction.

Finally, it is noteworthy that the relatively small sample of the paper did not allow for a deeper statistical analysis. Therefore, the differences between stakeholder views were only tested with non-parametric tests. In addition, larger samples may allow for testing differences between stakeholder views with multivariate models, also accommodating personal and demographic characteristics of the respondents. By so doing, the analysis will be able to disentangle the drivers of stakeholder perceptions between those emanating from their personal stance and beliefs and those arising from their role in the regional system. Finally, it should be noted that the response rate of the stakeholders was relatively low since only about one to three invited stakeholders responded despite the reminders that were sent. The low response rate could be attributed to the lack of established cooperation channels already identified as a barrier for university engagement. Therefore, for future studies, a careful strategy for the stakeholder engagement in the survey is strongly recommended.

Author Contributions: Conceptualization, M.A., S.N. and G.P.; methodology, S.N. and D.K.; software, S.N.; validation, M.A. and G.P.; data curation, M.A. and D.K.; writing-original draft preparation, M.A. and S.N.; writing-review and editing, D.K. and G.P.; visualization, M.A.; supervision, G.P.; project administration, M.A.; funding acquisition, M.A., S.N., D.K. and G.P. All authors have read and agreed to the published version of the manuscript. 
Funding: This research is co-financed by Greece and the European Union (European Social FundESF) through the Operational Programme "Human Resources Development, Education and Lifelong Learning 2014-2020" in the context of the project "Creating and Strengthening Comparative Advantage: The Region of Thessaly-University of Thessaly Cooperation Nexus" (MIS 5048958).

Institutional Review Board Statement: Not applicable.

Informed Consent Statement: Not applicable.

Data Availability Statement: Data are available upon request.

Acknowledgments: The authors would like to thank the participants of the 13th World Congress of the Regional Science Association International (RSAI), 25-28 May 2021 and the 60th European Regional Science Association (ERSA) Congress, 24-27 August 2021 as well as the three anonymous referees for their constructive comments and suggestions.

Conflicts of Interest: The authors declare no conflict of interest.

\section{References}

1. Thanki, R. How do we know the value of higher education to regional development? Reg. Stud. 1999, 33, 84-89.

2. Chatterton, P.; Goddard, J. The response of higher education institutions to regional needs. Eur. J. Educ. 2000, 35, 475-496. [CrossRef]

3. Trippl, M.; Sinozic, T.; Smith, H.L. The role of universities in regional development: Conceptual models and policy institutions in the UK, Sweden and Austria. Eur. Plan. Stud. 2015, 23, 1722-1740. [CrossRef]

4. Meyer, J.; Pillei, M.; Zimmermann, F.; Stöglehner, G. Customized education as a framework for strengthening collaboration between higher education institutions and regional actors in sustainable development-Lessons from Albania and Kosovo. Sustainability 2018, 10, 3941. [CrossRef]

5. $\quad$ Baber, Z.; Gibbons, M.; Limoges, C.; Nowotny, H.; Schwartzman, S.; Scott, P.; Trow, M. The New Production of Knowledge: The Dynamics of Science and Research in Contemporary Societies; SAGE: New York, NY, USA, 1995.

6. Garrido-Yserte, R.; Gallo-Rivera, M.T. The impact of the university upon local economy: Three methods to estimate demand-side effects. Ann. Reg. Sci. 2010, 44, 39-67. [CrossRef]

7. Monteiro, S.; Isusi-Fagoaga, R.; Almeida, L.; García-Aracil, A. Contribution of Higher Education Institutions to Social Innovation: Practices in Two Southern European Universities. Sustainability 2021, 13, 3594. [CrossRef]

8. Uyarra, E. Conceptualizing the Regional Roles of Universities, Implications and Contradictions. Eur. Plan. Stud. 2010, 18, 1227-1246. [CrossRef]

9. Youtie, J.; Shapira, P. Building an innovation hub: A case study of the transformation of university roles in regional technological and economic development. Res. Policy 2008, 37, 1188-1204. [CrossRef]

10. Florax, R.J.G.M. The University: A Regional Booster? Economic Impacts of Academic Knowledge Infrastructure; Avebury: Aldershot, UK, 1992; ISBN 978-1-85628-342-7.

11. Stachowiak, K.; Pinheiro, R.; Sedini, C.; Vaattovaara, M. Policies aimed at strengthening ties between universities and cities. In Place-Making and Policies for Competitive Cities; Musterd, S., Kovacs, Z., Eds.; John Wiley \& Sons, Ltd.: Chichester, UK, 2013; pp. 263-291. ISBN 978-1-118-55457-9.

12. Goldstein, H.A.; Maier, G.; Luger, M. The university as an instrument for economic and business development: US and European comparisons. In Emerging Patterns of Social Demand and University Reform: Through a Glass Darkly; Dill, D.D., Sporn, B., Eds.; Elsevier Science Inc.: Tarrytown, NY, USA, 1995; pp. 105-133.

13. Drucker, J.; Goldstein, H. Assessing the Regional Economic Development Impacts of Universities: A Review of Current Approaches. Int. Reg. Sci. Rev. 2007, 30, 20-46. [CrossRef]

14. Perry, L.; Farmer, B.; Onder, D.; Tanner, B.; Burton, C. A Community-based activities survey: Systematically determining the impact on and of faculty. Metrop. Univ. 2015, 26, 25-46.

15. Holton, V.L.; E Hinterlong, J.; Jettner, J. Assessment practices of community-engaged institutions in the USA: Common claims and uncertain methods. Res. Eval. 2020. [CrossRef]

16. Frondizi, R.; Fantauzzi, C.; Colasanti, N.; Fiorani, G. The Evaluation of Universities' Third Mission and Intellectual Capital: Theoretical Analysis and Application to Italy. Sustainability 2019, 11, 3455. [CrossRef]

17. Sedlacek, S. The role of universities in fostering sustainable development at the regional level. J. Clean. Prod. 2013, 48, 74-84. [CrossRef]

18. Mehling, S.; Kolleck, N. Cross-sector collaboration in Higher Education Institutions (HEIs): A critical analysis of an urban sustainability development program. Sustainability 2019, 11, 4982. [CrossRef]

19. Filho, W.L.; Vargas, V.R.; Salvia, A.L.; Brandli, L.L.; Pallant, E.; Klavins, M.; Ray, S.; Moggi, S.; Maruna, M.; Conticelli, E.; et al. The role of higher education institutions in sustainability initiatives at the local level. J. Clean. Prod. 2019, 233, 1004-1015. [CrossRef]

20. Demele, U.; Nölting, B.; Crewett, W.; Georgiev, G. Sustainability transfer as a concept for universities in regional transformationA case study. Sustainability 2021, 13, 4956. [CrossRef] 
21. United Nations. THE 17 GOALS I Sustainable Development. Available online: https://sdgs.un.org/goals (accessed on 11 August 2021).

22. Siegfried, J.J.; Sanderson, A.R.; McHenry, P. The economic impact of colleges and universities. Econ. Educ. Rev. 2007, 26, 546-558. [CrossRef]

23. Kotosz, B.; Lukovics, M.; Molnár, G.; Zuti, B. How to measure the local economic impact of universities? Methodological overview. Reg. Stat. 2015, 5, 3-19. [CrossRef]

24. Bramwell, A.; Wolfe, D.A. Universities and regional economic development: The entrepreneurial University of Waterloo. Res. Policy 2008, 37, 1175-1187. [CrossRef]

25. Urbano, D.; Guerrero, M. Entrepreneurial universities: Socioeconomic impacts of academic entrepreneurship in a European region. Econ. Dev. Q. 2013, 27, 40-55. [CrossRef]

26. Comunian, R.; Taylor, C.; Smith, D.N. The role of universities in the regional creative economies of the UK: Hidden protagonists and the challenge of knowledge transfer. Eur. Plan. Stud. 2013, 22, 2456-2476. [CrossRef]

27. Leon, I.; Oregi, X.; Marieta, C. Contribution of university to environmental energy sustainability in the city. Sustainability 2020, 12 , 774. [CrossRef]

28. Holton, V.L.; Jettner, J.F.; Shaw, K.K. Measuring community-university partnerships across a complex research university: Lessons and findings from a pilot enterprise data collection mechanism. Metrop. Univ. 2015, 26, 99-124.

29. Organisation for Economic Co-Operation and Development Higher Education and Regions: Globally Competitive, Locally Engaged; OECD: Paris, France, 2007; ISBN 978-92-64-03414-3.

30. Goddard, J.; Kempton, L. Connecting Universities to Regional Growth: A Practical Guide; European Union: Brussels, Belgium, 2011.

31. Benneworth, P.; Jongbloed, B.W. Who matters to universities? A stakeholder perspective on humanities, arts and social sciences valorisation. High. Educ. 2010, 59, 567-588. [CrossRef]

32. Ferrero-Ferrero, I.; Fernández-Izquierdo, M.Á.; Muñoz-Torres, M.J.; Bellés-Colomer, L. Stakeholder engagement in sustainability reporting in higher education: An analysis of key internal stakeholders' expectations. Int. J. Sustain. High. Educ. 2018, 19, 313-336. [CrossRef]

33. Geryk, M. Universities of the future: Universities in transition under the influence of stakeholders' changing requirements. In Advances in Human Factors, Business Management and Leadership; Kantola, J.I., Barath, T., Nazir, S., Eds.; Springer International Publishing: Cham, Germany, 2018; pp. 116-124.

34. Florida, R. Regions and universities together can foster a creative economy. Chron. High. Educ. 2006, 53, B6.

35. Lilles, A.; Rõigas, K. How higher education institutions contribute to the growth in regions of Europe? Stud. High. Educ. 2017, 42, 65-78. [CrossRef]

36. Deiaco, E.; Holmén, M.; Mckelvey, M. What does it mean conceptually that universities compete? In Learning to Compete in European Universities: From Social Institution to Knowledge Business; Edward Elgar Publishing: Cheltenham, UK, 2008.

37. Dyason, D.; Kleynhans, E.P. A university in a small city: Discovering which sectors benefit. Acta Commer. 2017, 17, 1-13. [CrossRef]

38. Koryakina, T.; Sarrico, C.S.; Teixeira, P.N. Third mission activities: University managers' perceptions on existing barriers. Eur. J. High. Educ. 2015, 5, 316-330. [CrossRef]

39. Norusis SPSS 140 Statistical Procedures Companion; Prentice Hall: Hoboken, NJ, USA, 2005; ISBN 978-0-13-199527-7.

40. Watkins, M.W. A Step-by-Step Guide to Exploratory Factor Analysis with SPSS, 1st ed.; Routledge: New York, NY, USA, 2021; ISBN 978-1-00-314934-7.

41. IBM KMO and Bartlett's Test. Available online: https:/ / prod.ibmdocs-production-dal-6099123ce774e592a519d7c33db8265e-0000 .us-south.containers.appdomain.cloud/docs/en/spss-statistics/23.0.0?topic=detection-kmo-bartletts-test (accessed on 2 August 2021).

42. Tavakol, M.; Dennick, R. Making sense of cronbach's alpha. Int. J. Med. Educ. 2011, 2, 53-55. [CrossRef]

43. Taber, K.S. The Use of Cronbach's Alpha When Developing and Reporting Research Instruments in Science Education. Res. Sci. Educ. 2018, 48, 1273-1296. [CrossRef]

44. Grice, J.W. Computing and evaluating factor scores. Psychol. Methods 2001, 6, 430-450. [CrossRef] [PubMed]

45. Burrows, J. Going beyond labels: A framework for profiling institutional stakeholders. Contemp. Educ. 1999, 70, 5-10.

46. Jongbloed, B.; Enders, J.; Salerno, C. Higher education and its communities: Interconnections, interdependencies and a research agenda. High. Educ. 2008, 56, 303-324. [CrossRef]

47. European Commission Region of Thessalia. Available online: https://ec.europa.eu/growth/tools-databases/regionalinnovation-monitor/base-profile/region-thessalia (accessed on 15 August 2021).

48. ELSTAT 2011 Population-Housing Census_ELSTAT. Available online: https://www.statistics.gr/en/2011-census-pop-hous (accessed on 15 August 2021).

49. University of Thessaly University Overview. Available online: http:/ / old.uth.gr/en/the-university/overview (accessed on 1 July 2021).

50. University of Thessaly Ranking. Available online: https://www.uth.gr/panepistimio/axiologisi-poiotita/seira-katataxis (accessed on 25 July 2021).

51. University of Thessaly Strategic Planning-Vision. Available online: https://www.uth.gr/panepistimio/me-mia-matia/ stratigikos-shediasmos-orama (accessed on 1 August 2021). 